\title{
Erratum to: California's nurse-to-patient ratio law and occupational injury
}

\author{
J. Paul Leigh · Carrie A. Markis • Ana-Maria Iosif • \\ Patrick S. Romano
}

Published online: 14 January 2015

(C) Springer-Verlag Berlin Heidelberg 2015

\section{Erratum to: Int Arch Occup Environ Health DOI 10.1007/s00420-014-0977-y}

Authors would like to publish an erratum to correct the error in the abstract and Table 2. The percentage differencein-differences estimate for licensed practical nurses (LPNs) values under the abstract and Table 2 are updated, and the corrected text and table are given below.

Results The most probable difference-in-differences estimate indicated that the California law was associated with 55.57 fewer occupational injuries and illnesses per 10,000
RNs per year, a value $31.6 \%$ lower than the expected rate without the law. The most probable reduction for LPNs was $38.2 \%$. Analyses of CIs suggested that these reductions were unlikely to be due to chance.

Conclusions Despite significant data restrictions and corresponding methodological limitations, the evidence suggests that the law was effective in reducing occupational injury and illness rates for both RNs and LPNs. Whether these 31.6 and $38.2 \%$ reductions are maintained over time remains to be seen.

The online version of the original article can be found under doi:10.1007/s00420-014-0977-y.

J. P. Leigh · P. S. Romano

Center for Healthcare Policy and Research, University

of California, Davis, School of Medicine, Sacramento, CA, USA

J. P. Leigh $(\bowtie)$

Department of Public Health Sciences, UC Davis Medical

School, MS1C Room 100, Davis, CA 95616-8638, USA

e-mail: pleigh@ucdavis.edu

C. A. Markis

Betty Irene Moore School of Nursing,

University of California, Davis, Sacramento, CA, USA

A.-M. Iosif

Division of Biostatistics, Department of Public Health Sciences,

University of California, Davis, School of Medicine,

Davis, CA, USA

P. S. Romano

Department of Internal Medicine, University of California, Davis,

School of Medicine, Sacramento, CA, USA 
Table 2 Comparisons for licensed practical nurses

\begin{tabular}{lll} 
Average injury rate $^{\mathrm{a}}$ & $\begin{array}{l}\text { Difference } \\
\text { ("before"-after" law) }\end{array}$ & $\begin{array}{l}95 \% \text { confidence interval for } \\
\text { the difference }\end{array}$ \\
\cline { 1 - 1 } Before law After law & & Lower bound Upper bound
\end{tabular}

Comparison \#1: average injury rate $00-03$ versus 05-08

\section{California}

USA-California

Difference-in-difference (percent reduction from California "before" law)

Comparison \#2: average injury rate $01-03$ versus 05-07

\section{California}

USA-California

Difference-in-difference (percent reduction from California "before" law)

Comparison \#3; average injury rate 99-03 versus 05-09

\section{California}

USA-California

Difference-in-difference (percent reduction from California "before" law)

$\begin{array}{rrcrr}244.27 & 90.27 & 154.01 & 80.397 & 227.623 \\ 167.86 & 107.07 & 60.78 & 44.058 & 77.502 \\ & & 93.23(38.2 \%) & & \end{array}$

$\begin{array}{rrrrr}209.18 & 97.00 & 112.17 & 39.908 & 184.432 \\ 164.64 & 112.93 & 51.71 & 34.894 & 68.529\end{array}$

$60.47(28.9 \%)$

$\begin{array}{rrlrr}229.95 & 90.67 & 139.28 & 67.213 & 211.347 \\ 171.00 & 103.67 & 68.33 & 51.509 & 85.151 \\ & & 70.95(30.9 \%) & & \end{array}$

${ }^{a}$ Average injury rates were calculated per 10,000 licensed practical nurses per year 